\title{
Critical Involvement of Extracellular ATP Acting on P2RX7 Purinergic Receptors in Photoreceptor Cell Death
}

\author{
Shoji Notomi, ${ }^{*}$ Toshio Hisatomi, ${ }^{* \dagger}$ \\ Takaaki Kanemaru, ${ }^{\ddagger}$ Atsunobu Takeda, ${ }^{*}$ \\ Yasuhiro Ikeda, ${ }^{*}$ Hiroshi Enaida, ${ }^{*}$ \\ Guido Kroemer, ${ }^{\$ \uparrow \| * \star \dagger \dagger}$ and Tatsuro Ishibashi* \\ From the Department of Ophthalmology, " and the Morphology \\ Core Unit, ${ }^{\ddagger}$ Graduate School of Medical Sciences, Kyushu \\ University, Fukuoka, Japan; the Department of Ophthalmology, ${ }^{\dagger}$ \\ National Hospital Organization Kyushu Medical Center, \\ Fukuoka, Japan; INSERM, U848, ${ }^{\S}$ Villejuif, France; the \\ Metabolomics Platform, " Institut Gustave Roussy, Villejuif, \\ France; the Centre de Recherche des Cordeliers, "Paris, France; \\ the Pôle de Biologie,** Hôpital Européen Georges Pompidou, \\ Paris, France; and the Sorbonne Paris Cité Faculté de \\ Médicine ${ }^{+\dagger}$ Université Paris Descartes, Paris, France
}

Stressed cells release ATP, which participates in neurodegenerative processes through the specific ligation of P2RX7 purinergic receptors. Here, we demonstrate that extracellular ATP and the more specific P2RX7 agonist, $2^{\prime}$ - and $3^{\prime}-O$-(4-benzoylbenzoyl)-ATP, both induce photoreceptor cell death when added to primary retinal cell cultures or when injected into the eyes from wild-type mice, but not into the eyes from $\mathbf{P} 2 \mathbf{R X} 7^{-/-}$mice. Photoreceptor cell death was accompanied by the activation of caspase- 8 and -9 , translocation of apoptosis-inducing factor from mitochondria to nuclei, and TUNEL-detectable chromatin fragmentation. All hallmarks of photoreceptor apoptosis were prevented by premedication or co-application of Brilliant Blue G, a selective P2RX7 antagonist that is already approved for the staining of internal limiting membranes during ocular surgery. ATP release is up-regulated by nutrient starvation in primary retinal cell cultures and seems to be an initializing event that triggers primary and/or secondary cell death via the positive feedback loop on P2RX7. Our results encourage the potential application of Brilliant Blue $G$ as a novel neuroprotective agent in retinal diseases or similar neurodegenerative pathologies linked to excessive extracellular ATP. (Am J Pathol 2011, 179:2798-2809; DOI: 10.1016/j.ajpath.2011.08.035)
Photoreceptor degeneration involves the activation of several pathways of regulated cell death that may constitute potential therapeutic targets. Accordingly, attempts have been undertaken to inhibit caspases, which play a central role in the acquisition of the apoptotic structure, ${ }^{1,2}$ although pharmacologic pan-caspase inhibitors have largely failed to preserve the structure and function of photoreceptors. ${ }^{3,4}$ Caspases can be activated as the result of mitochondrial outer membrane permeabilization (MOMP) in thus far that the mitochondrial release of cytochrome $c$ results in the Apaf-1 apoptosome-dependent activation of caspase-9. MOMP also results in the mitochondrial release of apoptosis-inducing factor (AIF), which then translocates to the nucleus and participates in caspase-independent peripheral chromatin condensation and large-scale DNA fragmentation, ${ }^{5}$ suggesting the existence of redundant cell death mechanisms downstream of MOMP. 4,6,7 Pharmacologic inhibition of MOMP has indeed been shown to confer some degree of neuroprotection in a model of photoreceptor degeneration induced by retinal detachment. ${ }^{4}$

Upstream of or independently from MOMP, death receptors from the tumor necrosis factor (TNF) receptor family proteins, including Fas receptor (Apo-1/CD95) or death receptor 4 , can transmit apoptotic and/or necrotic signals initiated by specific "death ligands." ${ }^{8}$ Increased TNF receptor or CD95 signaling can participate in photoreceptor death induced by retinal detachment, 9,10 in which case these receptors may either stimulate the initiation of apoptosis (via the activation of caspase-8) or programed necrosis (via the activation of RIP1 kinase).

Supported by the Ministry of Education, Science, Sports and Culture, Japan Grant-in-Aid for Scientific Research 21791690.

Accepted for publication August 23, 2011.

Supplemental material for this article can be found at http://ajp. amjpathol.org or at doi: 10.1016/j.ajpath.2011.08.035.

Address reprint requests to Tatsuro Ishibashi, M.D., Ph.D., Department of Ophthalmology, Graduate School of Medical Sciences, Kyushu University, 3-1-1 Maidashi Higashi-ku, Fukuoka, 812-8582, Japan; or Guido Kroemer, M.D., Ph.D., INSERM, U848, Institut Gustave Roussy, Pavillon de Recherche 1, 39 rue Camille-Desmoulins, F-94805 Villejuif, France. E-mail: ishi@eye.med.kyushu-u.ac.jp or kroemer@orange.fr. 
Indeed, simultaneous inhibition of caspases (with Z-VADfmk) and RIP1 kinase (with necrostatin 1) has a more pronounced neuroprotective effect on photoreceptors in retinal detachment than either treatment alone. ${ }^{11}$ Taken together, these results underscore the existence of multiple cell death mechanisms that have to be inhibited simultaneously to confer optimal neuroprotection.

An alternative to the inhibition of executioner pathways consists in intercepting the initiating events that account for upstream damage signals. Recently, ATP has been discovered as a main extracellular messenger that can contribute to lethal signaling. ${ }^{12}$ ATP, which can be released via exocytosis, anion channels, or transporters, can act in autocrine and paracrine signaling pathways, ${ }^{13}$ for instance by evoking action potentials in brain slices, isolated nerves, and glial cells, ${ }^{14}$ indicating that ATP acts as a physiological mediator of neurotransmission and neuron-glia communication. ${ }^{15}$ Moreover, extracellular ATP concentrations increase in spinal cord injury, ${ }^{16}$ chronic neuropathic pain, ${ }^{17}$ and brain ischemia, ${ }^{18}$ suggesting a pathologic role for extracellular ATP as well. Extracellular ATP can act on purinergic receptors, which are classified into two classes, the ionotropic, ligandgated $\mathrm{P} 2 \mathrm{X}$ receptors and the metabotropic, $\mathrm{G}$ proteincoupled $P 2 Y$ receptors. ${ }^{19}$ Among the seven mammalian P2X receptors, ${ }^{20}$ the $\mathrm{P} 2 \mathrm{X} 7$ receptor (P2RX7) has the highest affinity for ATP. P2RX7 differs from other P2X receptor subtypes by its long cytoplasmic, carboxy-terminal tail (240 amino acids). Brief application of agonists renders P2RX7 permeable to small cations $\left(\mathrm{K}^{+}, \mathrm{Na}^{+}\right.$, $\mathrm{Ca}^{2+}$ ) similar to other P2X receptors, ${ }^{12}$ whereas repeated or prolonged exposure to agonists can lead to the formation of P2RX7-dependent pores that become permeable to solutes $\leq 900 \mathrm{Da}$, hence triggering cell death. ${ }^{21}$ Thus, extracellular ATP can induce apoptotic and/or necrotic cell death by acting on P2RX7 ${ }^{22}$ Despite the great interest in the carboxyl-terminal region of P2RX7, the mechanism by which P2RX7 mediates apoptotic signaling is largely unknown. Of note, the residues 436 to 531 of P2RX7 are similar to a region of TNF receptor 1 that overlaps its death domain, ${ }^{23}$ which has led to the proposal of a potential mechanism for P2RX7-induced caspase- 8 activity and apoptosis. ${ }^{24}$ Thus, the plasma membrane receptor, P2RX7, may cleave and activate caspase-8 during extrinsic apoptotic pathway.

Importantly, P2RX7 is widely expressed in various organs, including the immune system (thymus or spleen) ${ }^{21}$ and the central nervous system (cortex, hippocampus, ${ }^{25}$ and spinal $\operatorname{cord}^{26}$ ). P2RX7 is expressed on astrocytes, microglial cells, and neurons. ${ }^{14}$ In the retina, P2RX7 is expressed on Müller glia, ${ }^{27}$ and in both inner and outer retinal neurons, including retinal ganglion cells ${ }^{28,29}$ and photoreceptors. ${ }^{30}$ Genetic or functional inactivation of P2RX7 can attenuate the development of several neurodegenerative diseases, including Alzheimer's disease $^{31}$ and Huntington's disease. ${ }^{32}$ Thus, systemic administration of a pharmacologic P2RX7 antagonist, Brilliant Blue G (BBG) can confer neuroprotective effects in models of Alzheimer's, Parkinson's disease, and spinal cord injury. ${ }^{31-33}$
BBG is a triphenylmethane dye that has been approved for intraoperative use in ocular surgery, in the context of chromovitrectomy, which involves the use of vital dyes to improve the visualization of intraocular tissues during vitrectomy, thereby improving specific procedures such as internal limiting membrane peeling. ${ }^{34}$ Driven by the recent characterization of BBG as a P2RX7 antagonist, ${ }^{31-33}$ we decided to investigate the pathogenic implications of P2RX7 in pathologic photoreceptor loss, as well as the therapeutic utility of BBG in this context. As a result of these investigations, we report here that increased extracellular ATP levels contribute to pathologic conditions of photoreceptor loss and that BBG efficiently avoids photoreceptor cell death.

\section{Materials and Methods}

\section{Animals}

All animal experiments were performed according to the guidelines of the Association for Research in Vision and Ophthalmology on adult (8 weeks of age) male C57BL6JJcl mice (CLEA, Tokyo, Japan) and isogenic $\mathrm{P} 2 \mathrm{RX} 7^{-1-}$ mice kindly provided from Pfizer Inc. (Groton, CT; now also available from The Jackson Laboratory, Bar Harbor, ME; B6.129P2-P2rx $7^{\text {tm1Gab }} / \mathrm{J}$, stock number 005576).

\section{Adult Mouse Primary Retinal Cell Cultures}

Adult primary retinal cell cultures were prepared as previously described with minor modifications. ${ }^{6}$ Primary retinal cells were cultured in 4-well chamber (Nunc; part of Thermo Fisher Scientific, Rochester, NY) with Neurobasal-A medium (Invitrogen, Carlsbad, CA) containing B27 supplement without antioxidants (Invitrogen), 1 $\mu \mathrm{g} / \mathrm{mL}$ insulin, and $12 \mu \mathrm{g} / \mathrm{mL}$ gentamicin. To determine the number of adherent photoreceptor cells, immunofluorescent staining was performed with a rabbit anti-recoverin antibody (Millipore, Bedford, MA).

For nutrient starvation, primary retinal cells were cultured for 3 hours (ATP measurement) or 24 hours (immunocytochemistry and viability assay) with Neurobasal-A medium without B27 supplement as "starvation medium." P2RX7 agonists [ATP or 2' - and 3'-O-(4-benzoylbenzoyl)ATP (BzATP); Sigma-Aldrich, St Louis, MO] or P2RX7 antagonists (1-[N, O-bis(5-isoquinolinesulphonyl)-N-methylL-tyrosyl]-4-phenylpiperazine (KN-62) or BBG; SigmaAldrich) were added to the medium and incubated for 24 hours. To investigate the effect of BBG before incubation, cells were cultured in the presence of BBG for 30 minutes, washed two times with culture medium, and incubated for 24 hours. To examine the secondary effects of death ligands, rat anti-mouse TNF- $\alpha$ neutralizing antibody (1 to $10 \mathrm{ng} / \mathrm{mL}$ MP6-XT22; R\&D Systems, Minneapolis, MN) ${ }^{35}$ or hamster anti-mouse CD95 ligand-neutralizing antibody (1 to $10 \mu \mathrm{g} / \mathrm{mL}$ MFL3; BD Biosciences, San Jose, CA $)^{36}$ was added to culture medium, whereas isogenic rat or hamster IgG was added as control. 


\section{Viability Assay in Primary Retinal Cell Cultures}

To assess the viability of primary retinal cells, we used calcein AM (2 $\mu \mathrm{mol} / \mathrm{L}$; Invitrogen) or MitoTracker Orange CMTMRos (200 nmol/L, M7510; Invitrogen) that were added for 34 minutes to primary retinal cell cultures. Then, cultured cells were fixed with $4 \%$ paraformaldehyde, and photoreceptors were labeled with recoverin. Calcein $^{+}$or $\mathrm{CMTMRos}^{+}$photoreceptors were counted in 10 random fields by blinded observers with the use of Image J software version 1.38x ( $\mathrm{NIH}$, Bethesda, MD). Values are given as means \pm SDs of 10 replicate wells.

\section{Intraocular Injections}

For evaluation of the toxicity of BzATP and the effect of $\mathrm{BBG}$ in vivo, we took advantages of gas compression vitrectomy for uniform diffusion of intravitreally injected solutions. Mouse eyes were vitrectomized with SF6 gas as we and others previously described. ${ }^{37-40}$ To investigate the effects of gas compression vitrectomy on the viability of retinal cells, we observed ophthalmic examination every day up to 2 weeks and evaluated histochemical changes in H\&E staining and TUNEL-positive cells in the retina at 3 and 14 days after gas injections. Two weeks after gas injection, mice were anesthetized with an intraperitoneal injection of pentobarbital, and their pupils were dilated with topical $1 \%$ tropicamide and $2.5 \%$ phenylephrine hydrochloride. Then, $2 \mu \mathrm{L}$ of liquid (PBS supplemented with 10 to $20 \mathrm{mmol} / \mathrm{L}$ BzATP or BzATP plus $500 \mu \mathrm{mol} / \mathrm{L}$ BBG) was injected into the vitreous cavity with a 32-gauge needle on a Hamilton syringe through posterior to the limbus. Intraocular injections were only performed in the right eye of each animal, and five eyes were examined in each group. The mice were sacrificed 24 hours after treatment, and their eyes were harvested, frozen at nitrogen liquid temperature, and cryosectioned for histochemical or ultrastructural examinations.

\section{TUNEL Analysis}

TUNEL analysis and quantification of TUNEL-positive cells were performed as previously described ${ }^{4}$ with the use of the ApopTag Fluorescein In Situ Apoptosis Detection Kit (Millipore). Nuclei were counterstained with propidium iodide or Hoechst 33342. TUNEL-positive cells in the outer nuclear layer (ONL) were counted by two blinded observers, and results were presented as means \pm SDs.

\section{Immunohistochemistry}

As previously reported, ${ }^{6}$ rabbit anti-AIF (R\&D Systems), anti-mouse cleaved caspase-9 (Cell Signaling Technology, Beverly, MA), anti-mouse cleaved caspase-8 (Cell Signaling Technology), and anti-recoverin (Millipore) were used as primary antibodies and incubated at $4^{\circ} \mathrm{C}$ overnight. Goat anti-rabbit IgG conjugated to Alexa Fluor 546 or 647 (Invitrogen) were used as secondary antibodies and incubated at room temperature for 1 hour.

\section{Electron Microscopy}

The posterior segments of enucleated eyes were fixed in PBS containing 1\% glutaraldehyde and 1\% paraformaldehyde, postfixed in veronal acetate buffer osmium tetroxide (2\%), dehydrated in ethanol and water, and embedded in Epon. Primary retinal cell cultures were similarly fixed, dehydrated, and embedded in Epon. Ultrathin sections were cut from blocks and mounted on copper grids. The specimens were observed with $\mathrm{H}-7650$ transmission electron microscope (Hitachi, Tokyo, Japan).

\section{Calcium Imaging}

Primary retinal cells were cultured on 35-mm coverslip dishes (BD Biosciences) in Neurobasal-A medium with B27 supplement. Then the calcium indicator, Fluo-4 AM (5 $\mu \mathrm{mol} / \mathrm{L}$; Invitrogen) was loaded onto primary cultures. The calcium-dependent fluorescence of Fluo-4 was captured by microscopy during 20 minutes of incubation after adding $1 \mathrm{mmol} / \mathrm{L}$ BzATP or vehicle PBS. To evaluate the effect of chelation of extracellular $\mathrm{Ca}^{2+}$ or P2RX7 antagonist (BBG), the fluorescence of Fluo-4 was measured in culture medium containing $1 \mathrm{mmol} / \mathrm{L}$ EGTA (Sigma-Aldrich) or $10 \mu \mathrm{mol} / \mathrm{L} \mathrm{BBG}$, respectively.

\section{ATP Measurements}

For ATP measurements of culture medium, primary retinal cells were starved for 3 hours with Neurobasal-A medium without B27 supplement as starvation cultures, and cultures with Neurobasal-A medium with B27 supplement were prepared as controls. Then $100 \mu \mathrm{L}$ of culture medium was collected, centrifuged at $4^{\circ} \mathrm{C}$, and subjected to ATP measurements as follows. The ATP levels of collected medium (100 $\mu \mathrm{L}$ in 96-well microplates; BD Biosciences) were immediately determined by adding luciferin-luciferase reaction buffer (ATP bioluminescent assay kit, FL-AA; Sigma-Aldrich) and a multimode microplate reader, Flex Station 3 (Molecular Devices, Sunnyvale, CA). The ATP levels in medium of "control cultures" were determined by calibration of standard ATP in Neurobasal-A medium with/without B27 supplement. To define the detection limit, ecto-nucleotidase (Apyrase; $10 \mathrm{U} / \mathrm{mL}$; Sigma-Aldrich) was added to culture medium. In control experiments, $\beta, \gamma$-methylene-ATP, a potent ecto-ATPase inhibitor (300 $\mu \mathrm{mol} / \mathrm{L}$; Sigma-Aldrich), was added to control or starvation cultures. Values are given as mean \pm SD of 10 replicate wells.

\section{Imaging of ATP Release}

Primary retinal cells were cultured on 35-mm coverslip dishes (BD Biosciences) in Neurobasal A medium with B27 supplement. ATP assay mix (a part of the FL-AA kit; Sigma-Aldrich) was added to culture media (one vial per $1.5 \mathrm{~mL}$ of culture medium with/without B27 supplement). Light production from the luciferin-luciferase reaction was captured by an electron multiplier charge-coupled camera (ImagEM; Hamamatsu Photonics, Shizuoka, 


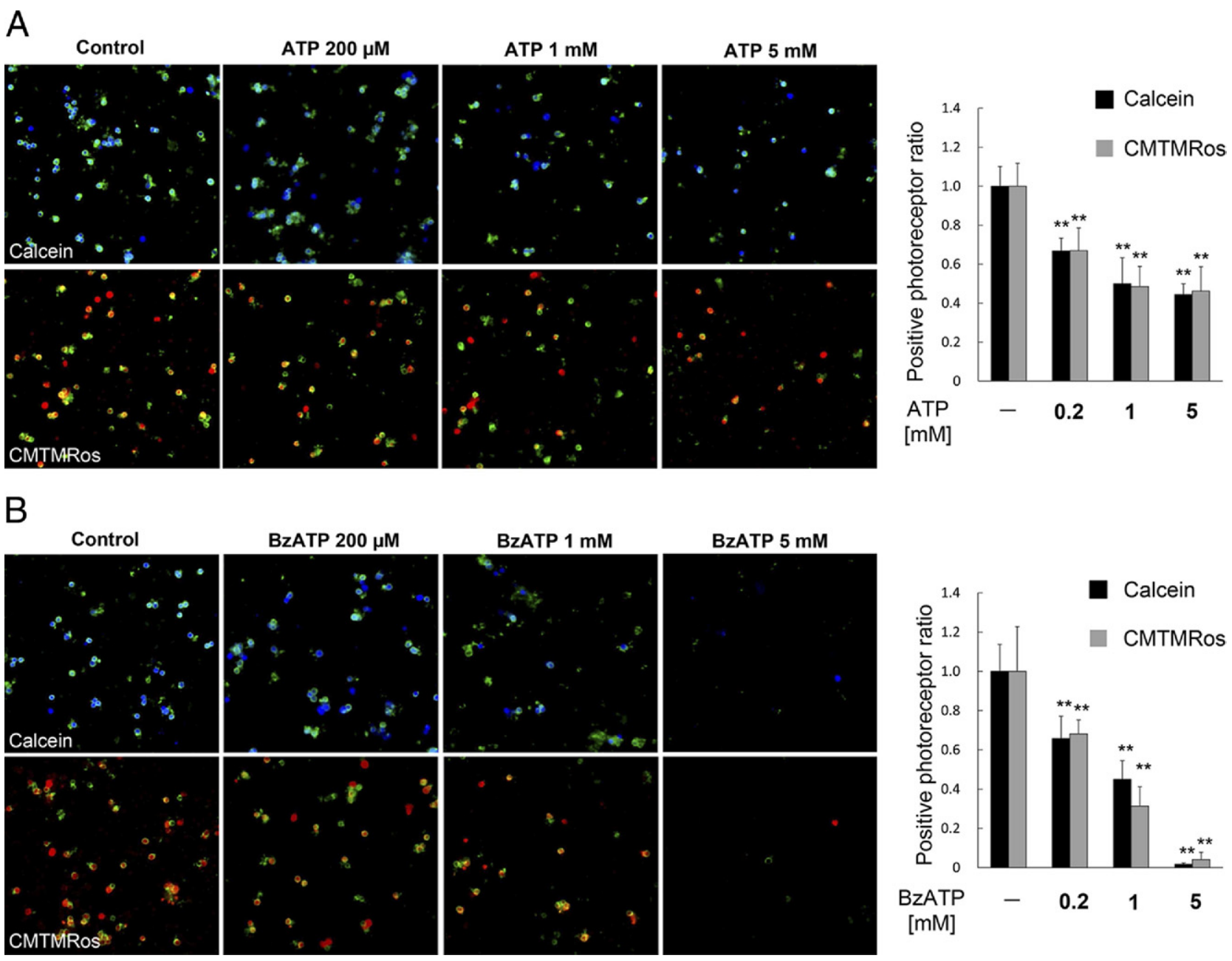

Figure 1. P2RX7 agonists induced retinal cell death in primary retinal cell cultures. The viability of retinal cells was assessed by incubation with calcein AM or MitoTracker CMTMRos after 24 hours of culture with ATP or BzATP. Photoreceptors were labeled by immunocytochemistry for recoverin (in green). A: The frequency of calcein ${ }^{+}$(top panels; in blue) or $\mathrm{CMTMRos}^{+}$(bottom panels; in red) photoreceptors decreased after incubation with $200 \mu \mathrm{mol} / \mathrm{L}$ to 5 mmol/L ATP in a dose-dependent manner. B: BzATP also reduced calcein ${ }^{+}$(top panels) or CMTMRos $^{+}$(bottom panels) photoreceptors in a dose-dependent fashion. These quantifications are shown in the right panels in $\mathbf{A}$ and $\mathbf{B} .{ }^{*} P<0.05 ;{ }^{* *} P<0.01$.

Japan) with a 40x oil lens (NA 1.35; Olympus, Tokyo, Japan) for 3 hours during 5-minute exposure periods.

\section{Statistical Analysis}

Statistical differences between two groups were analyzed with the Mann-Whitney U-test. Multiple group comparison was performed by analysis of variance followed by Tukey-Kramer adjustments. Differences were considered significance at $P<0.05$ and $P<0.01$. All values were expressed as means \pm SDs.

\section{Results}

\section{P2RX7 Mediated Photoreceptor Death in Primary Retinal Cell Cultures}

To investigate the possible implication of P2RX7 in photoreceptor degeneration, we took advantage of primary retinal cell cultures. ${ }^{6,41}$ Photoreceptor viability was assessed with two fluorescent sensors, calcein AM and MitoTracker CMTMRos, which only label intact and nonapoptotic, metabolically active cells, respectively. Calcein AM, which is nonfluorescent and cell permeable, becomes fluorescent and is trapped in live cells after removal of the AM moiety by cellular esterases. Cells that stain with this dye hence must possess an intact, impermeable plasma membrane. The lipophilic cation MitoTracker CMTMRos labels mitochondria, driven by the mitochondrial transmembrane potential; hence, it stains cells with intact mitochondrial membranes. The addition of ATP (Figure 1A) or BzATP (Figure 1B), a potent, more selective P2RX7 agonist, ${ }^{21}$ resulted in a dose-dependent decline of viable, calcein $^{+}$or CMTMRos ${ }^{+}$photoreceptors that were identified by immunofluorescence detection of recoverin. Before starting blocking experiments by BBG, we tested whether BBG has potential toxicity. Primary retinal cell cultures were incubated in the presence or absence of 1 to $10 \mu \mathrm{mol} / \mathrm{L}$ BBG for 24 hours. No significant decline of photoreceptor viability was ob- 
A

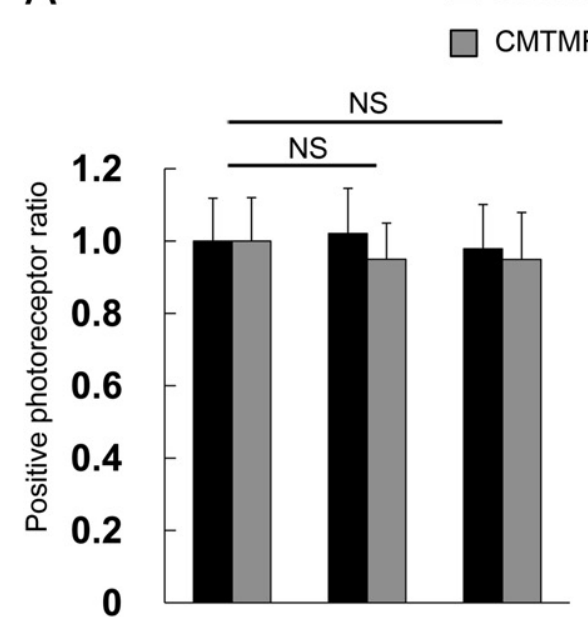

$\mathrm{BBG}[\mu \mathrm{M}] \quad-\quad 10$

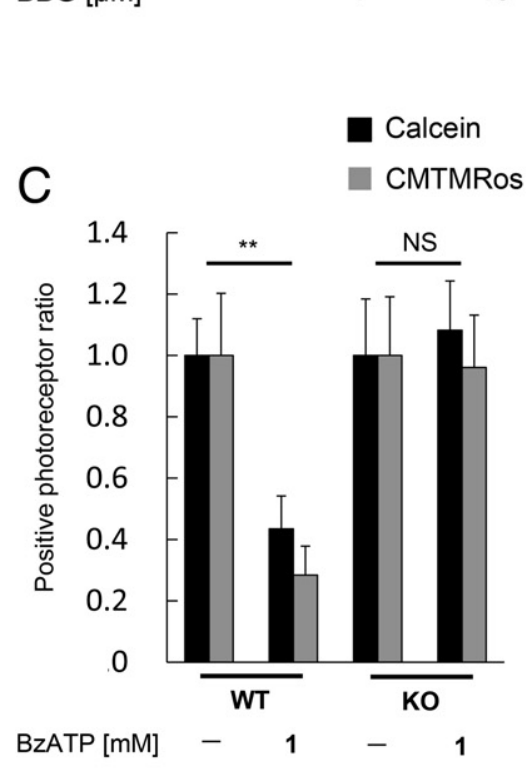

alcein

CMTMRos
B

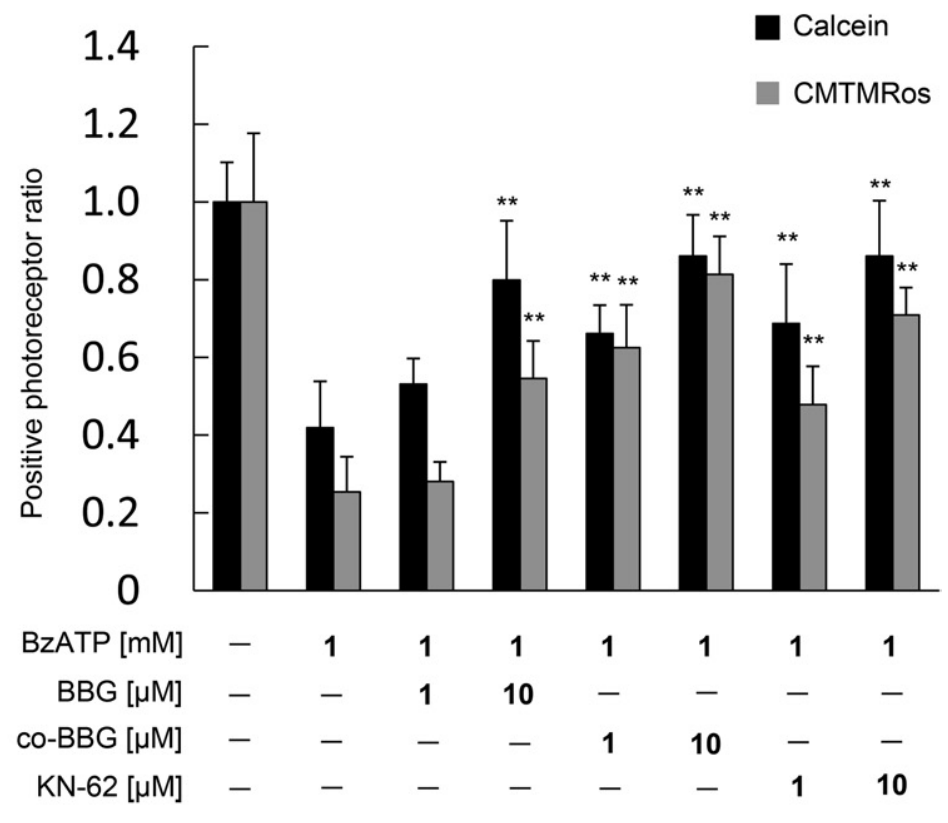

$\mathrm{E}$

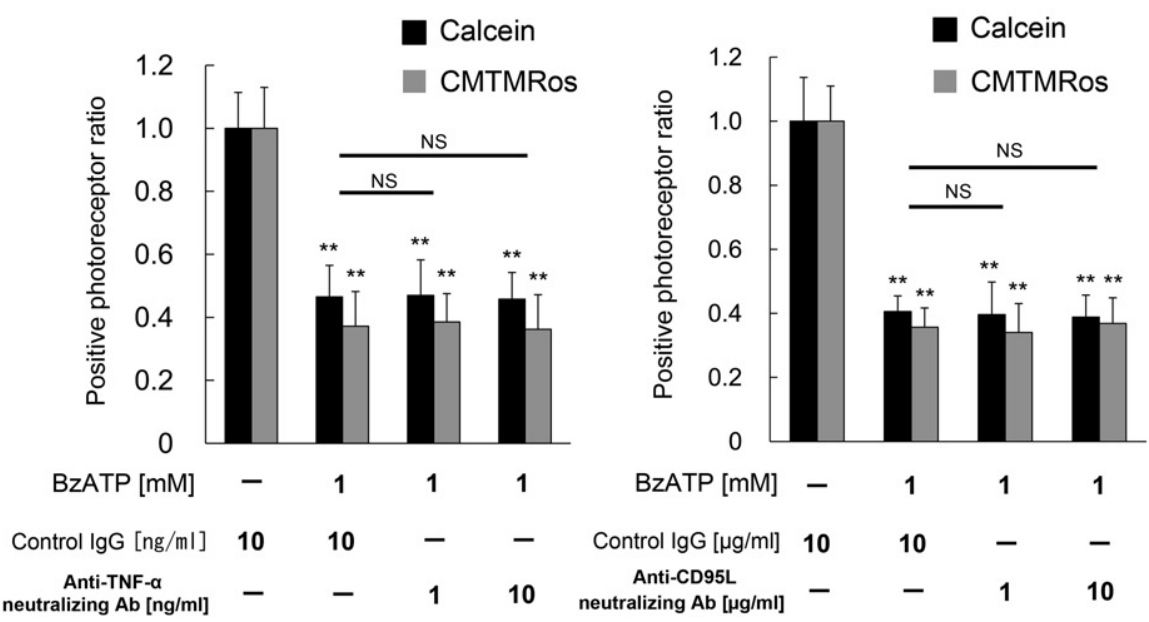

Figure 2. BBG attenuated photoreceptor death as a P2RX7 antagonist. A: The viability of photoreceptors after 24 hours of continuous incubation with 1 to 10 $\mu \mathrm{mol} / \mathrm{L}$ BBG. B: Photoreceptor death (induced by $1 \mathrm{mmol} / \mathrm{L}$ BzATP) was partially reversed by 30 minutes of transient incubation (BBG) or 24 hours of continuous incubation (CO-BBG) of 1 to $10 \mu \mathrm{mol} / \mathrm{L} \mathrm{BBG}$ or 1 to $10 \mu \mathrm{mol} / \mathrm{L} \mathrm{KN}-62$. C: Photoreceptor viability was preserved in BzATP-treated (1 mmol/L, 24 hours) photoreceptors from P2RX7 $7^{-/-}$mice (KO) compared with wild-type (WT) controls. D and E: Neutralizing antibody against TNF- $\alpha$ (MP6-XT22) or CD95 ligand (MFL3) failed to prevent BzATP-induced photoreceptor death; $n=10$ per group. Scale bar $=20 \mu \mathrm{m}$. ${ }^{* *} P<0.01$.

served (Figure 2A). BBG showed minimal toxicity at those concentrations in vitro. BBG, a potent P2RX7 antagonist, ${ }^{42}$ as well as another selective P2RX7 inhibitor, $\mathrm{KN}-62$, reduced BzATP-induced photoreceptor death (Figure $2 \mathrm{~B}$ ). BBG is a noncompetitive and slowly reversible $\mathrm{P} 2 \mathrm{R} X 7$ inhibitor that antagonizes $\mathrm{P} 2 \mathrm{R} X 7$ by allosteric regulation. ${ }^{42}$ Accordingly, a short (30 minutes) pre-incubation with BBG could reduce BzATPinduced photoreceptor death to some extent, although less efficiently than continuous co-incubation (Figure 2B). Of note, photoreceptors isolated from $\mathrm{P} 2 \mathrm{R} \times 7^{-1-}$ mice readily survived exposure to high-dose BzATP (1 $\mathrm{mmol} / \mathrm{L})$ under conditions in which large numbers of wild-type photoreceptors died, underscoring that these effects are truly specific (Figure 2C).

These results indicated the specific effect of $\mathrm{P} 2 \mathrm{RX} 7$ on photoreceptor death. However, we needed to exclude the secondary effect of death ligands, which could potentially be released by other cell types, on photoreceptor death. To this end, we performed the blocking experiment by neutralizing antibody against TNF- $\alpha$ and CD95 ligand. Of note, neither TNF- $\alpha$ ( 1 to 10 $\mathrm{ng} / \mathrm{mL}$ MP6-XT22) ${ }^{35}$ nor CD95 ligand (1 to $10 \mu \mathrm{g} / \mathrm{mL}$ MFL3) ${ }^{36}$ neutralizing antibody could prevent the photoreceptor death induced by $1 \mathrm{mmol} / \mathrm{L}$ BzATP (Figure 2, $D$ and $E$ ). These results suggest that $P 2 R \times 7$ stimu- 
A
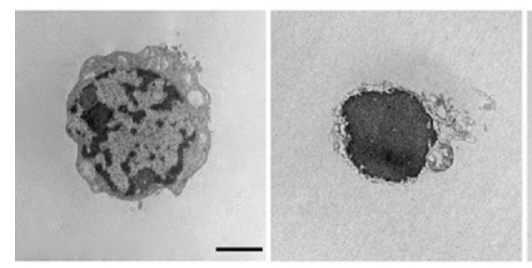

C

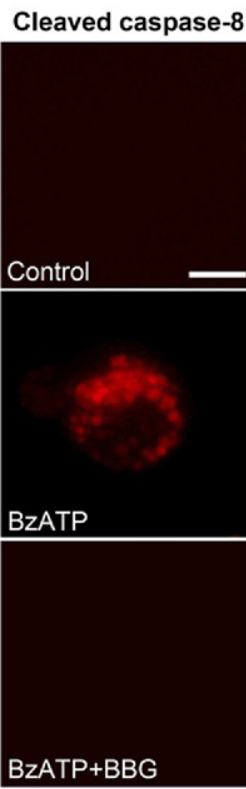

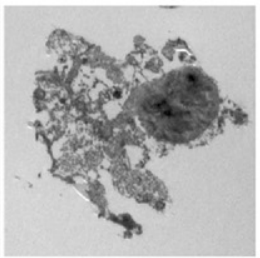

B

D

TUNEL

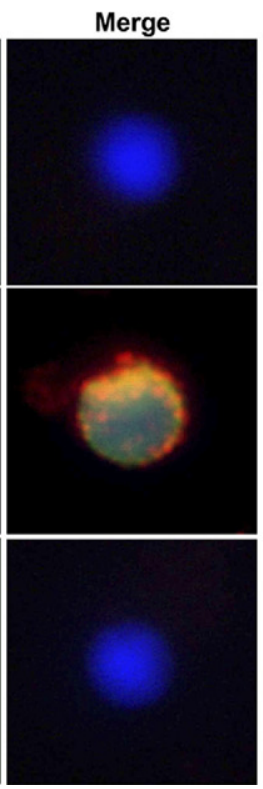

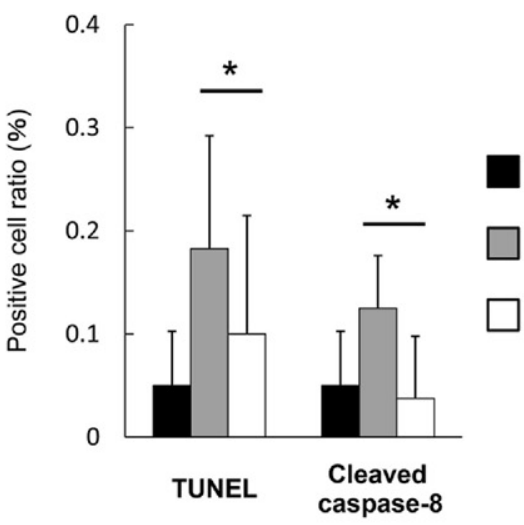

Control

BzATP

$B z A T P+B B G$

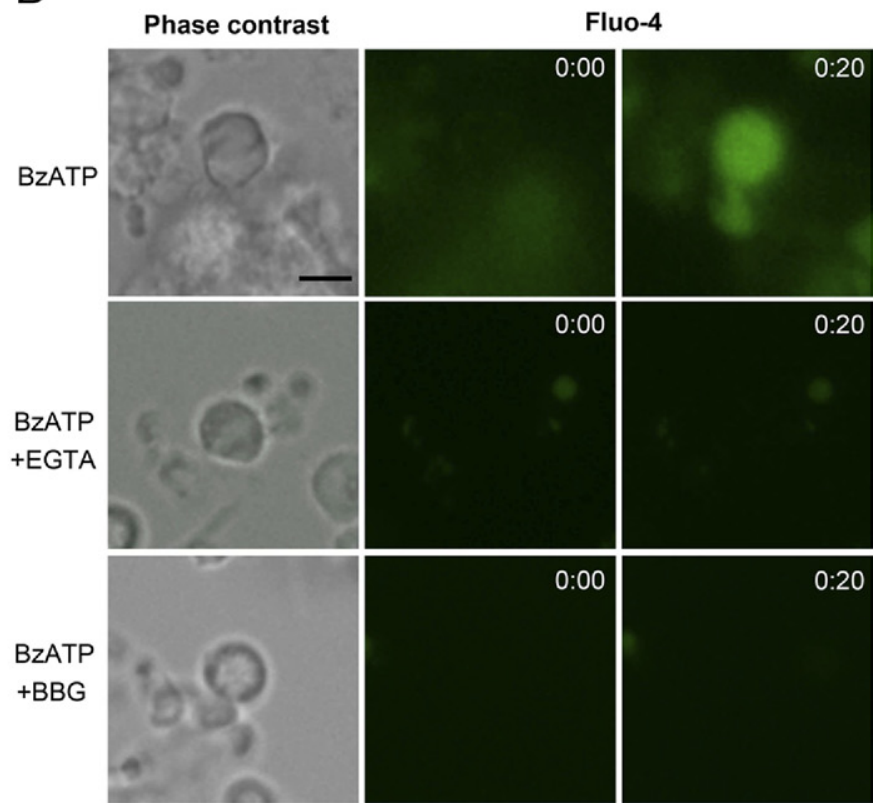

Figure 3. P2RX7 induced caspase-8 cleavage and calcium influx in vitro. A: Electron microscopy showed the relatively well-preserved organelle of photoreceptors in primary cultures without BzATP administration (left panel). Apoptotic cell death was observed with chromatin condensation (middle panel) afte BzATP administration. Necrotic cell death could also be detected after BzATP (right panel). Scale bar $=2 \mu \mathrm{m}$. B: Quantified results of cleaved caspase- $8^{+}$or TUNEL $^{+}$cells after $1 \mathrm{mmol} / \mathrm{L}$ BzATP administration in the presence or absence of $10 \mu \mathrm{mol} / \mathrm{L}$ BBG in primary cultures; $n=10$ per group. $* P<0.05$. C: Representative images of immunocytochemistry for cleaved caspase- 8 (left panels, cleaved caspase- 8 in red; middle panels, TUNEL in green; right panes, merged with Hoechst 33342 in blue). Cytoplasmic caspase- 8 cleavage was detected in TUNEL-positive cells after BzATP administration and decreased by BBG treatment. D: The fluorescent images of calcium indicator Fluo- 4 in primary retinal cell cultures before and 20 minutes after BzATP administration. The phase contrast images are shown in the left panels. The BzATP-induced increase of Fluo-4 fluorescence (top panels) was attenuated by adding 1 mmol/L EGTA (middle panels) or $10 \mu \mathrm{mol} / \mathrm{L}$ BBG (bottom panels). Scale bar $=5 \mu \mathrm{m}$.

lation could directly mediate the cell death pathway on photoreceptors, rather than an indirect pathway being mediated via TNF- $\alpha$ or CD95 ligands released by other cells.

\section{P2RX7 Induced Retinal Cell Death via Calcium Influx and Caspase-8 Activation}

Transmission electron microscopy showed the relatively well-preserved organelles in the photoreceptors without BzATP administration, whereas P2RX7 stimulation by BzATP resulted in apoptotic cell death, characterized by chromatin condensation, as well as in some instances in necrotic cell death (Figure 3A). After culture in the presence of $1 \mathrm{mmol} / \mathrm{L}$ BzATP, a significant percentage of photoreceptors exhibited a type of apoptotic DNA frag- mentation that could be detected with the TUNEL. To examine caspase-8 activation by P2RX7, TUNEL-positive cells also were stained by immunofluorescence with an antibody that only recognizes active, proteolytically mature caspase-8 (Figure 3C). BBG largely prevented these BzATP-induced signs of the extrinsic cell death pathway (Figure 3, B and C).

As to be expected for an ionotropic receptor, BzATP also stimulated a rapid (20 minutes) increase in intracelIular $\mathrm{Ca}^{2+}$ concentrations determined with Fluo-4 AM, a $\mathrm{Ca}^{2+}$ indicator that was loaded into primary cultures (Figure 3D, top panels). We performed the extracellular $\mathrm{Ca}^{2+}$ chelating with EGTA to clarify the origin of the $\mathrm{Ca}^{2+}$ increase. This increase of intracellular $\mathrm{Ca}^{2+}$ was attenuated by adding $1 \mathrm{mmol} / \mathrm{L}$ EGTA into the culture medium (Figure 3D, middle panels), indicating that BzATP medi- 
ated $\mathrm{Ca}^{2+}$ influx mainly through the cation channel not via release from intracellular binding proteins. Furthermore, co-incubation of $10 \mu \mathrm{mol} / \mathrm{L}$ BBG inhibited the $\mathrm{Ca}^{2+}$ influx by BzATP (Figure 3D, bottom panels), suggesting that BBG prevents intracellular calcium signaling by blocking the P2RX7 ion channel.

In conclusion, P2RX7 ligation kills photoreceptors via the influx of $\mathrm{Ca}^{2+}$ and caspase-8 activation, suggesting a potential mechanism for the P2RX7-mediated extrinsic pathway in line with previous reports. 23,24

\section{Photoreceptor Apoptosis Induced by Intraocular Administration of P2RX7 Agonists in Vivo}

To determine whether P2RX7 ligation can trigger retinal cell death in vivo, we measured retinal cell apoptosis 24 hours after intraocular injection of $20 \mathrm{mmol} / \mathrm{L}$ BzATP into the eyes of C57BL/6 mice. The BzATP injections were performed 14 days after gas compression vitrectomy to obtain uniform diffusion of the injected solutions. Neither ophthalmic abnormality (ie, corneal edema) nor signs of retinal cell loss in H\&E staining were observed $\leq 14$ days after gas injection (data not shown), and no TUNELpositive cells were observed in the retina at 3 and 14 days after injections (Figure 4A). The intraocular injection of BzATP induced TUNEL-positive apoptotic events in the ganglion cell layer, which is notoriously susceptible to induction of apoptosis by stimulation of P2RX7 receptors, ${ }^{29,43,44}$ as well as in the inner nuclear layer and ONL. These TUNEL-detectable DNA degradations accompanied the caspase-8 cleavage (Figure 4B). In vivo apoptosis induction by BzATP was blunted by co-injection of $500 \mu \mathrm{mol} / \mathrm{L}$ BBG (Figure 4, C and D). As in the in vitro system, even high doses of BzATP (10 to $20 \mathrm{mmol} / \mathrm{L}$ ) largely failed to induce apoptosis when injected into P2RX7 $7^{-1-}$ mice (Figure 4, C and D). Transmission electron microscopy confirmed that BzATP induced the death of photoreceptors with hallmarks of apoptosis, such as cell shrinkage and chromatin condensation in the ONL. Moreover, BzATP caused the degeneration of pedicles and spherules in the outer plexiform layer. The frequency of apoptotic events and degenerative changes in rod spherules and cone pedicles was decreased when BzATP was combined with BBG (Figure 4E).

Taken together, these results confirmed that pharmacologic P2RX7 agonists have the potential to induce retinal cell death in vivo, under conditions in which P2RX7 antagonists can preserve photoreceptors.

\section{BBG Attenuates Starvation-Induced Photoreceptor Death in Primary Retinal Cell Cultures}

Primary retinal cells cultured under starvation conditions (Neurobasal A medium without B27 supplement, a serum substitute) exhibited a significantly elevated level of photoreceptor apoptosis compared with control cells (cultured in complete, B27-supplemented Neurobasal A medium). AlF was detected in the cytoplasm of control cultures, yet translocated into nuclei containing frag- mented DNA on starvation in agreement with our previous report that starvation induced the mitochondrial cell death pathway in photoreceptors. ${ }^{6}$ BBG treatment attenuated the starvation-induced AIF translocation and TUNEL staining (Figure 5, A and C). The proteolytic maturation of caspase- 9 was rarely detected in control cells, yet increased on starvation, an effect that was again reduced by BBG (Figure 5, B and C).

Similarly, a 24-hour starvation period led to a decrease in the frequency of viable $\left(\right.$ calcein $\left.^{+}\right)$and metabolically active $\left(\mathrm{CMTMRos}^{+}\right.$) photoreceptors to approximately one-half of that found in control cultures. This decline was again reversed by 30 minutes of pre-incubation with 0.1 to $10 \mu \mathrm{mol} / \mathrm{L}$ BBG in a dose-dependent manner (Figure 5D). Moreover, P2RX7 ${ }^{-1-}$ photoreceptors showed a significantly greater survival rate $(P<0.05)$ under starvation conditions (ratio of calcein ${ }^{+}$cells over controls $=0.73$; ratio of $\mathrm{CMTMRos}^{+}$cells over controls $=0.64$ ) compared with wild-type photoreceptors (ratio for calcein ${ }^{+}$cells $=$ 0.52; ratio for $\mathrm{CMTMRos}^{+}$cells $=0.50$ ). These results indicate that P2RX7 blockade inhibits the caspase-dependent and caspase-independent arms of the mitochondrial cell death pathway activated by starvation.

\section{Extracellular ATP in Stressed Retinal Cell Cultures}

Retinal cell cultures spontaneously released ATP $(0.22 \pm$ $0.06 \mathrm{nmol} / \mathrm{L})$ under the control conditions. This release increased significantly $(P<0.01)$ to $0.38 \pm 0.07 \mathrm{nmol} / \mathrm{L}$ on starvation, as quantified by a luciferase-based commercial assay (Figure 6). This difference persisted in the presence of $\beta, \gamma$-methylene-ATP, a potent inhibitor of ecto-ATPases ${ }^{45}$ that degrade extracellular ATP, suggesting that the increase in ATP concentrations induced by starvation results from ATP release rather than from reduced ATP degradation. Of note, adding BBG reduced the starvation-induced ATP release (Figure 6), suggesting the existence of a positive feedback loop that links activation of $\mathrm{P} 2 \mathrm{RX} 7$ receptors to nucleotide release ${ }^{46}$ For a more direct investigation of ATP release, we monitored retinal cell cultures by videomicroscopy to detect ATPdependent bioluminescence shown by a luciferin-luciferase assay. The frequency of ATP-releasing cells was low in control cultures, increased on starvation, and was again decreased when starved cells were pre-incubated with BBG (Figure 7). Thus, BBG inhibits ATP released from starved retinal cells.

\section{Discussion}

In the present work, we provide compelling evidence that extracellular ATP and activation of P2RX7 may contribute to the pathologic loss of photoreceptors. Thus, adding P2RX7 agonists to primary retinal cultures or their intraocular injection causes the apoptotic death of photoreceptors in a fashion that strictly depends on P2RX7, as shown by the use of $\mathrm{P} 2 \mathrm{R} \times 7^{-1-}$ mice. This death is accompanied by hallmarks of apoptosis, including the activation of caspases, the mitochondrio-nuclear translo- 
A
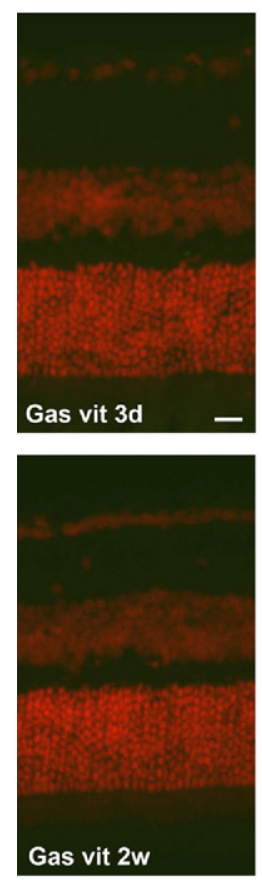

D

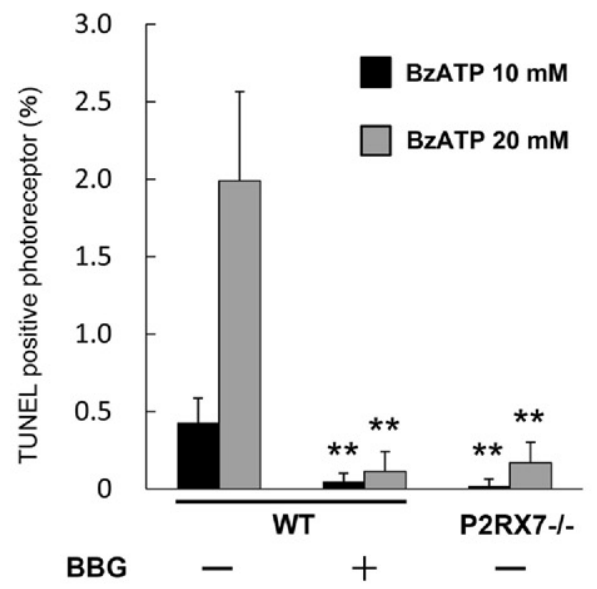

B
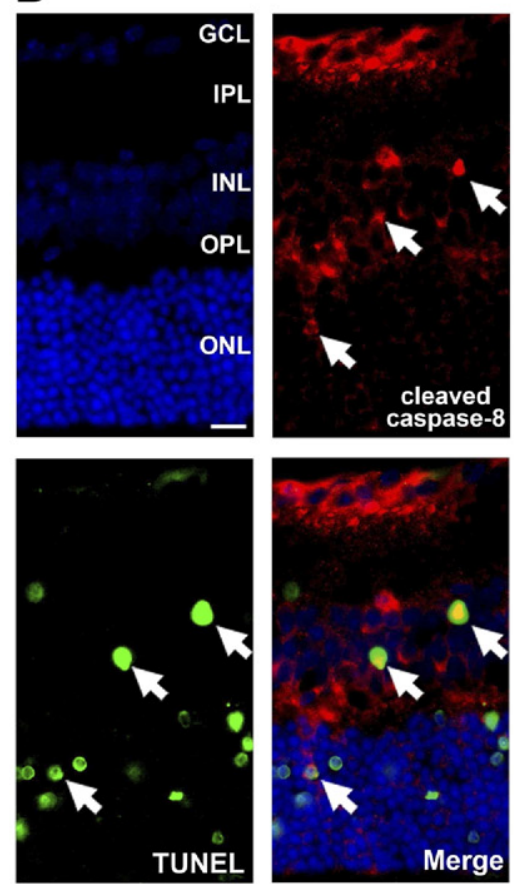

\section{C}
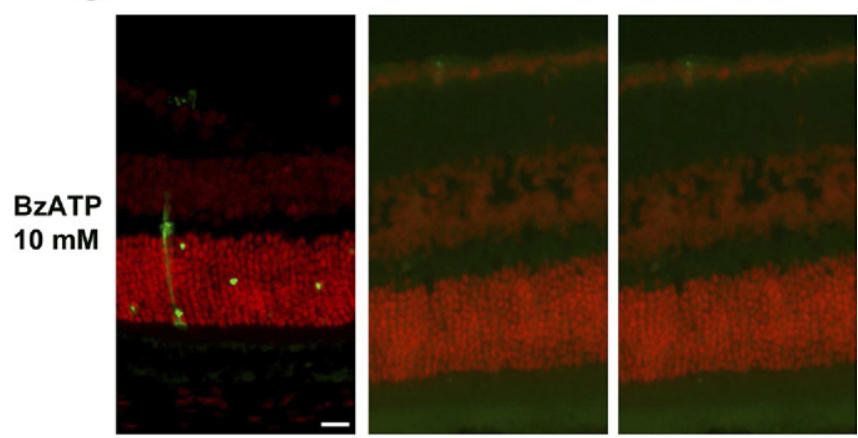

BZATP
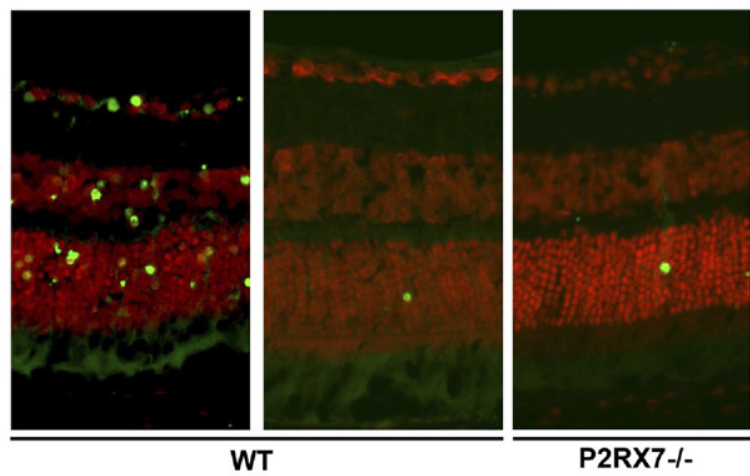

P2RX7-I-

BBG -

$E$

BzATP
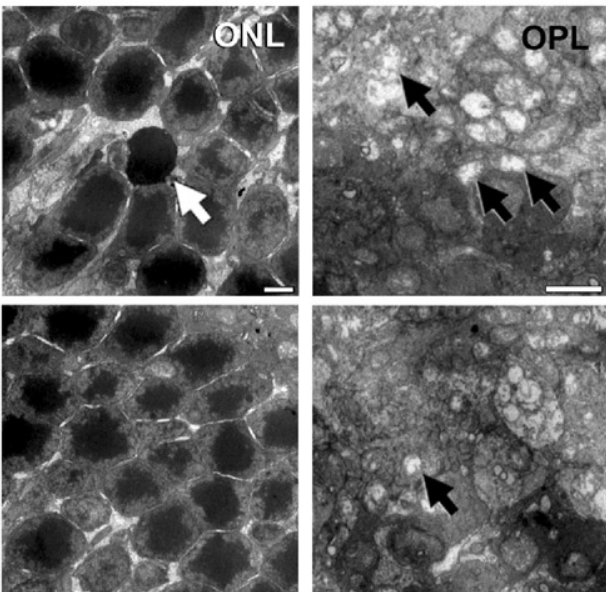

Figure 4. P2RX7 stimulation induced photoreceptor apoptosis/necrosis in vivo. A: Representative TUNEL (in green) and propidium iodide (in red) staining of mouse retina after 3 (top panel) and 14 (bottom panel) days of gas vitrectomy. B: Representative images of cleaved caspase- 8 in the mouse retina at 24 hours after the intraocular injection of $20 \mathrm{mmol} / \mathrm{L}$ BzATP (top left panel, Hoechst 33342 in blue; top right panel, cleaved caspase- 8 in red; bottom left panel, TUNEL in green; bottom right panel, merged). In wild-type mice, cleaved caspase-8-positive staining was observed in TUNEL-positive apoptotic cells in the inner nuclear layer (INL) and the outer nuclear layer (ONL) after the vitreous injection of BzATP (white arrows). GCL, ganglion cell layer; IPL, inner plexiform layer. C: The BzATP injections dose-dependently induced photoreceptor apoptosis in the ONL, as detected by TUNEL (left panels), and this effect was decreased by Co-injection of $500 \mu \mathrm{mol} / \mathrm{L} \mathrm{BBG}$ (middle panels). Only very few TUNEL-positive photoreceptors were detected on injection of BzATP into P2RX7 ${ }^{-/-}$mice (right panels). TUNEL stainings are shown in green and propidium iodide in red. The quantitations are shown in $\mathbf{D} ; n=6$ per group. Scale bar $=20 \mu \mathrm{m}$. ** $P<0.01$. E: Transmission electron microscopy showed BzATP-treated photoreceptors with characteristics of apoptosis, cell shrinkage, and chromatin condensation (white arrow) in the ONL and degenerated pedicles and spherules in the outer plexiform layer (OPL; black arrows). Apoptotic photoreceptors were decreased, and rod spherules and cone pedicles were well preserved in mice receiving BzATP plus BBG. Scale bar $=2 \mu \mathrm{m}$.

cation of AIF, and TUNEL-detectable chromatin fragmentation. Finally, we demonstrate that a pharmacologic P2RX7 antagonist, BBG, can prevent all stigmata of pathologic loss of photoreceptors by inhibiting extracellular ATP acting on P2RX7.

$B B G$ is reported to be a selective antagonist of P2RX7. ${ }^{42}$ In the current study, BBG substantially inhibited the effects of the selective P2RX7 agonist BzATP, namely, cell death, caspase- 8 activation, and calcium influx. To clarify the specificity of the BBG, we examined another known selective P2RX7 blocker, KN-62. KN-62 showed an effect similar to BBG. Furthermore, the examination with P2RX7 knockout mice showed the specificity of $B B G$ in vitro and in vivo. Thus, we concluded that BBG selectively blocked P2RX7 activation, thereby contributing a neuroprotective effect. Moreover, the blocking ex- 
A
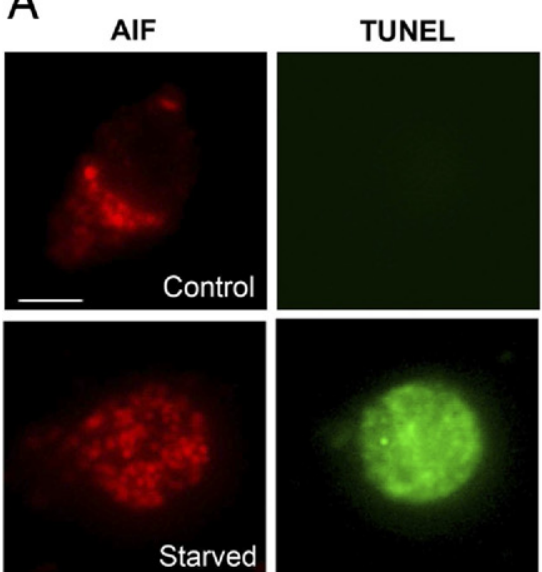

Starved
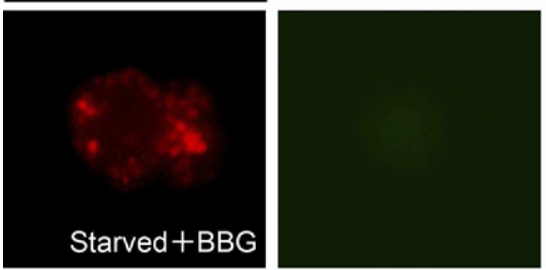

Merge
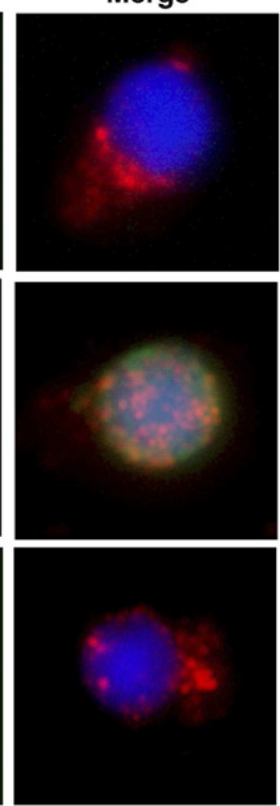

B Cleaved caspase-9
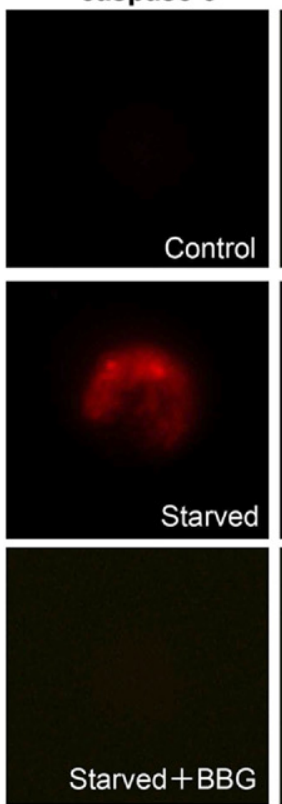

D
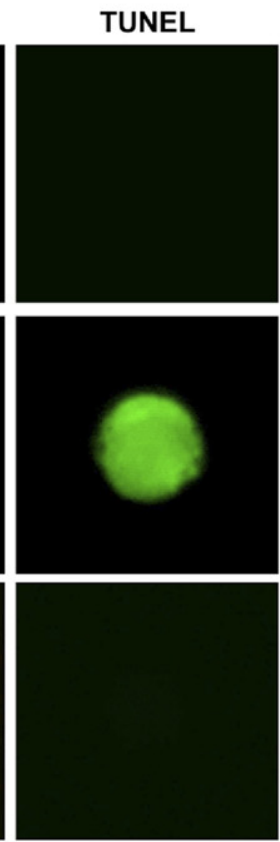

Control

Starved

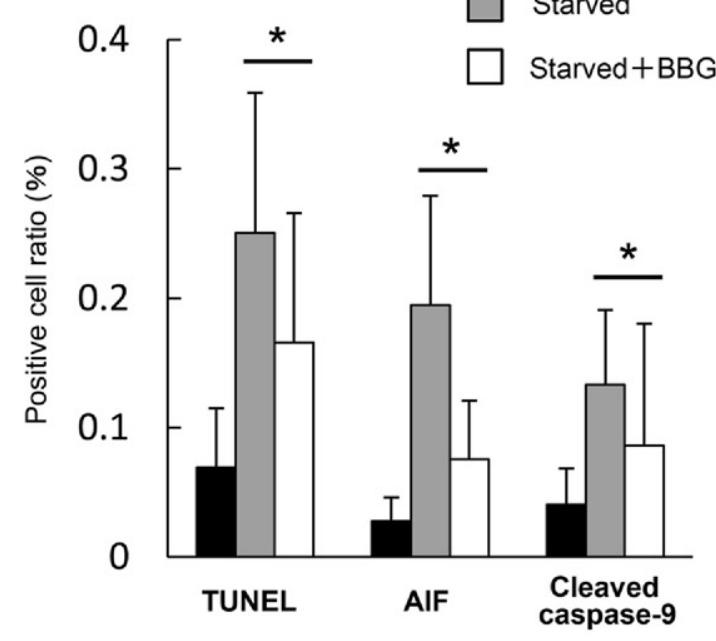

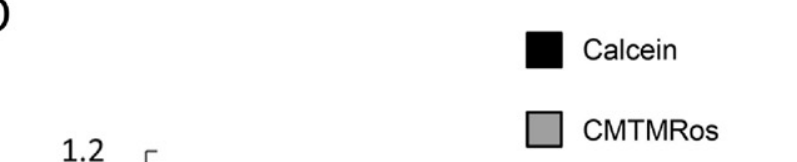

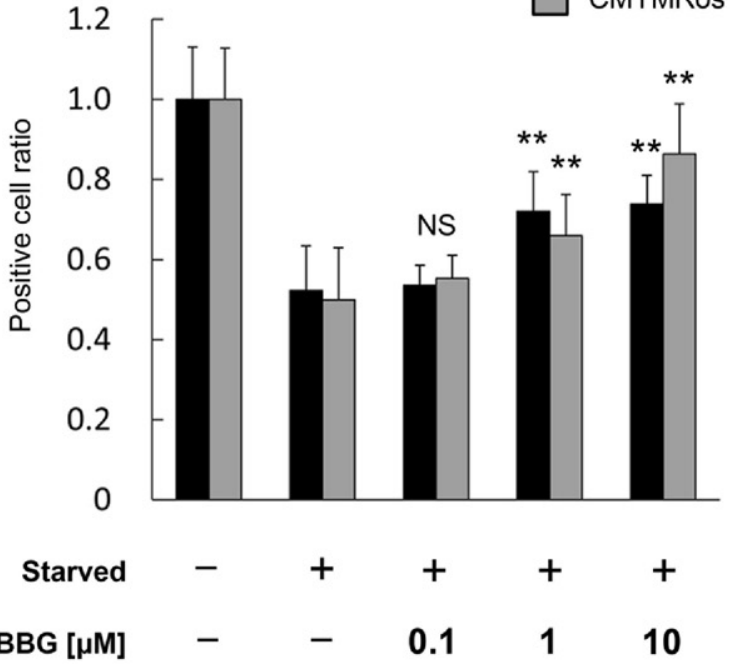

Figure 5. Neuroprotective effects of BBG in primary retinal cell cultures. A and B: Representative images of immunofluorescence detection of AIF (AIF in red, TUNEL in green, Hoechst33342 in blue) and cleaved caspase-9 (cleaved caspase-9 in red, TUNEL in green, Hoechst33342 in blue) in control cultures and after starvation in the absence or presence of BBG. Scale bar $=5 \mu \mathrm{m}$. The quantitations are shown in $\mathbf{C} ; n=10$ per group. ${ }^{*} P<0.05$. D: The dose-dependent neuroprotective effect of BBG; $n=10$ per group. ${ }^{* *} P<0.01$.

periment with neutralizing antibodies for TNF- $\alpha$ or CD95 ligand showed that P2RX7 could directly induce cell death on photoreceptors rather than indirectly via death ligands released by other cells.

ATP release appears to be (one of) the initializing event(s) that drives retinal cell death by nutrient starvation, a pathologic setting in vitro. Furthermore, the extracellular ATP released from dying cells may worsen the pathology by promoting the death of neighboring cells, namely, secondary cell death. The following potential mechanisms may account for the increase in extracellular
ATP in ocular pathologies. First, acute cell lysis may constitute one source of ATP, in line with the observations that ATP is released by acute stresses such as ischemia, ${ }^{18}$ hypotony, ${ }^{47}$ or oxygen/glucose deprivation. ${ }^{48}$ However, here we observed ATP release from retinal cells in a model of nutrient starvation well before the occurrence of cell death, ${ }^{6,41}$ suggesting that ATP release occurred through a more controlled mechanism than acute cell lysis. Second, massive ATP release may occur from the usurpation of a physiological mechanisms of release (when ATP serves as a neurotransmitter), per- 


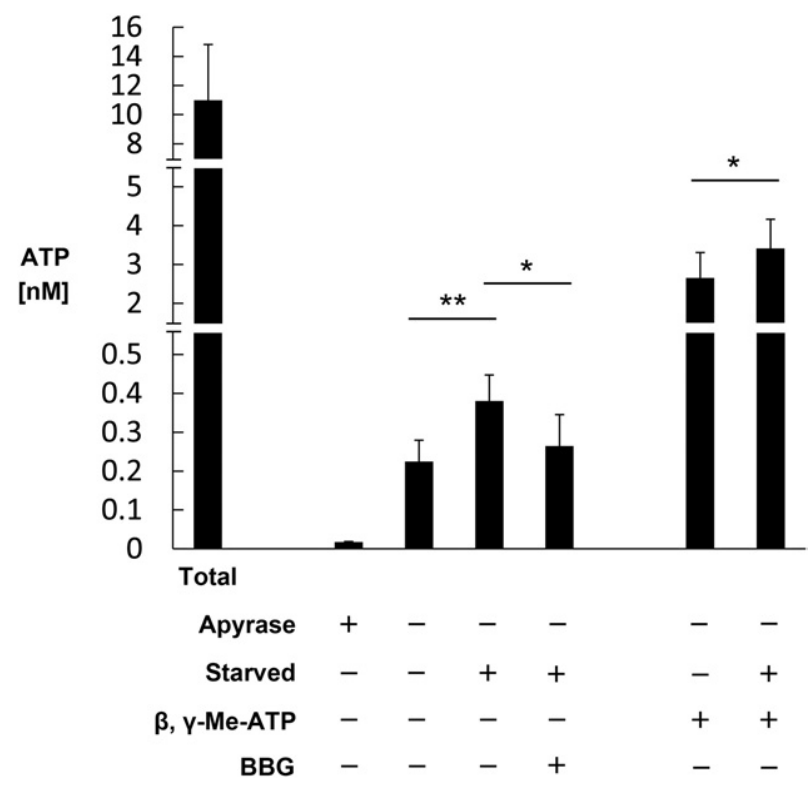

Figure 6. Nutrient starvation-induced ATP release from primary retinal cells in vitro. The ATP levels in primary culture were measured by luciferinluciferase assay. Total cellular levels of ATP were measured after permeabilization of plasma membranes, whereas the inferior detection limit of ATP levels was determined by adding apyrase to the culture supernatant fluids. Starvation was induced as in Figure 4 in the presence or absence of BBG or the ecto-ATPase inhibitor, $\beta, \gamma$-methylene-ATP ( $\beta, \gamma$-Me-ATP); $n=10$ per group. $* P<0.05,{ }^{* *} P<0.01$.

haps as the result of a pathogenic feed-forward loop. Indeed, it has been shown that extracellular ATP can stimulate further ATP release through the opening of P2RX7 channels, ${ }^{46}$ and, as shown here, BBG can reduce ATP release from starved retinal cultures by blocking the positive feedback.

The doses of ATP required to induce photoreceptor cell death are higher than those measured in starved cultures (which are rescued by adding BBG or knockout of P2RX7). There are three possible explanations for this discrepancy. First, ATP released from cells may be diffused into bulk culture medium and continuously degraded through the action of ecto-ATPases, which are active both in cultures ${ }^{45}$ and in vivo ${ }^{49}$ in the central nervous system. Indeed, the local concentration of ATP acting on the plasma membrane exceeds the micromolar level, as detected with membrane-bound protein A luciferase as a spatially localized probe of ATP levels at the extracellular cell surface. ${ }^{50}$ Hence, the local increase of ATP in the intercellular space may activate P2RX7 in retinal disorders. Second, the injected solutions diffuse into the intraocular cavity and can be washed out by aqueous humor circulation in vivo, thereby lowering the local concentration in the retina. Third, the function of P2RX7 may be modulated not only by extracellular ATP but also by local receptor modifications. Nagasawa et $\mathrm{al}^{51}$ reported that $\mathrm{P} 2 \mathrm{RX} 7$ channel opening may occur without exogenous ATP administration in cultured brain astrocytes, suggesting P2RX7 activation by endogenous ATP. Furthermore, P2RX7 may also be sensitized to ATP after ADP ribosylation at the arginine 125 position of $\mathrm{P} 2 \mathrm{RX} 7 .^{52}$ These results may provide additional alternative pathways for the activation of $\mathrm{P} 2 \mathrm{R} X 7$ under pathologic conditions. Further investigations will be needed to elucidate the exact details of P2RX7 activation with respect to fluctuating local ATP concentrations.

In this study, we have shown that BBG may have important neuroprotective effects on the retina. Of note, $\mathrm{BBG}$ is already approved for intraocular use in patients, for the surgical procedure of chromovitrectomy. This procedure initially involved the administration of indocyanine green as an intraocular surgical adjuvant in 2000. ${ }^{53,54}$ However, on our initial description that indocyanine green has toxic side effects in 2002, ${ }^{39}$ the following clinical and
Control
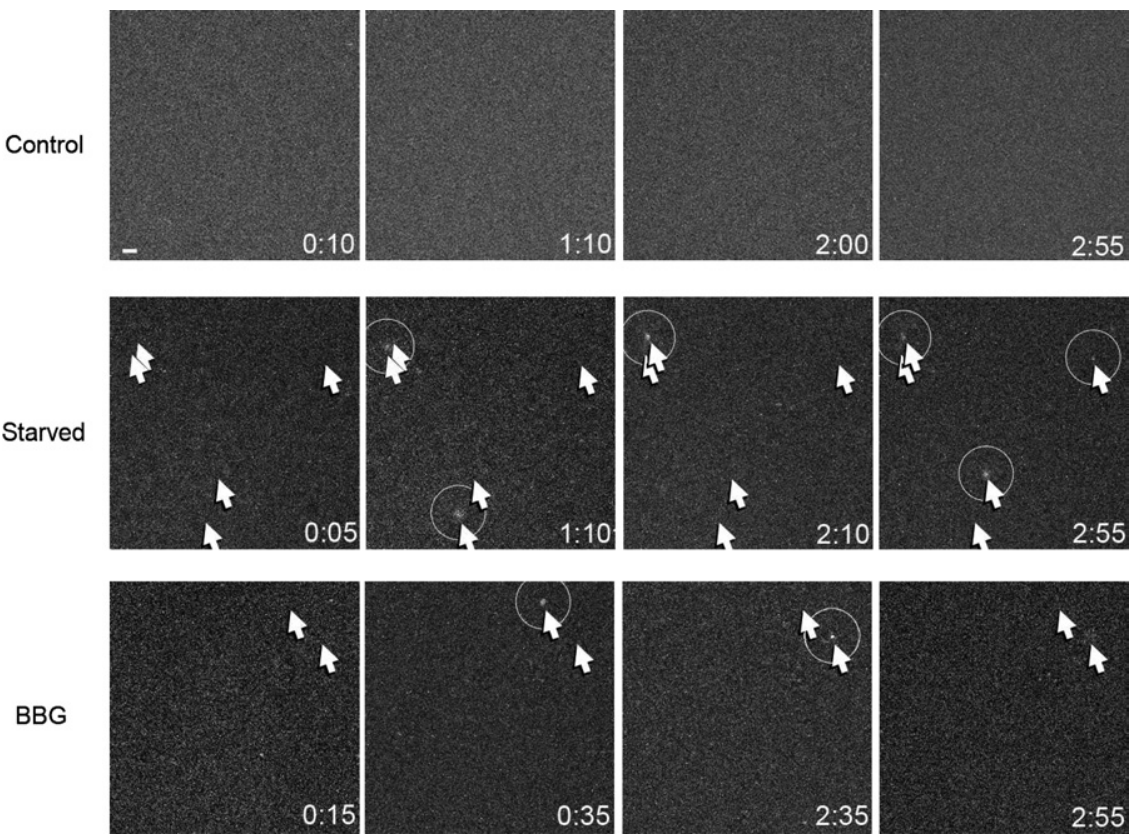

Figure 7. Time-lapse imaging of ATP release induced by starvation. For dynamic imaging of the ATP release, light production from the luciferinluciferase reaction was captured by an electron multiplier charge-coupled camera for 3 hours. Representative images are shown (see Supplemental Videos S1-S3 at http://ajp.amjpathol.org for total time-lapse images). Circles in the middle and bottom panels indicate events of ATP release induced by starvation, and arrows indicate the same location during the observation periods. Scale bar $=10 \mu \mathrm{m}$ 
experimental studies reported that indocyanine green induces visual field defects or retinal pigment epithelial atrophy. ${ }^{55-57}$ BBG has been introduced as an alternative staining dye for capsular staining in cataract surgery and chromovitrectomy with satisfactory biocompatibility. ${ }^{40,58,59}$ Moreover, whereas indocyanine green exposure turned out to trigger apoptotic signaling with caspase activation, BBG has minimal cytotoxicity in retinal cells. ${ }^{57}$ In the present study, we further confirmed the minimal toxicity of BBG with the primary culture. Recent reports have supported the safety of BBG as a surgical adjuvant, ${ }^{60-62}$ encouraging the ever expanding clinical applications for BBG in vitreoretinal surgery.

A substantial neuroprotective effect of BBG could be obtained at a dose of $\leq 10 \mu \mathrm{mol} / \mathrm{L}$, which is considerably lower than the concentration recommended for use during chromovitrectomy (293 $\mu \mathrm{mol} / \mathrm{L})$. Moreover, the neuroprotective effect of BBG could be obtained through transient exposures of primary cultures, probably because of the characteristics as a slowly reversible antagonist of P2RX7. Considering these results, one might expect BBG to have a broad, long-lasting neuroprotective effect in ocular pathologies. Taken together, our study clarifies (part of) the mechanisms through which BBG exerts its therapeutic effects in clinically relevant models of neurodegenerative diseases ${ }^{31-33}$ and thereby lend support to the potential application of BBG as a novel neuroprotective agent.

\section{Acknowledgments}

We thank Mari Imamura and Fumiyo Morikawa (Kyushu University) for technical assistance. We thank Olympus Corporation (Tokyo, Japan) for provision of electron multiplier CCD technology.

\section{References}

1. Ellis HM, Horvitz HR: Genetic control of programmed cell death in the nematode C. elegans. Cell 1986, 44:817-829

2. Yuan J, Shaham S, Ledoux S, Ellis HM, Horvitz HR: The C. elegans cell death gene ced-3 encodes a protein similar to mammalian interleukin-1 beta-converting enzyme. Cell 1993, 75:641-652

3. Green DR, Kroemer G: Pharmacological manipulation of cell death: clinical applications in sight? J Clin Invest 2005, 115:2610-2617

4. Hisatomi T, Sakamoto T, Murata T, Yamanaka I, Oshima Y, Hata Y, Ishibashi T, Inomata H, Susin SA, Kroemer G: Relocalization of apoptosis-inducing factor in photoreceptor apoptosis induced by retinal detachment in vivo. Am J Pathol 2001, 158:1271-1278

5. Susin SA, Lorenzo HK, Zamzami N, Marzo I, Snow BE, Brothers GM, Mangion J, Jacotot E, Costantini P, Loeffler M, Larochette N, Goodlett DR, Aebersold R, Siderovski DP, Penninger JM, Kroemer G: Molecular characterization of mitochondrial apoptosis-inducing factor. Nature 1999, 397:441-446

6. Hisatomi T, Nakazawa T, Noda K, Almulki L, Miyahara S, Nakao S, Ito Y, She H, Kohno R, Michaud N, Ishibashi T, Hafezi-Moghadam A Badley AD, Kroemer G, Miller JW: HIV protease inhibitors provide neuroprotection through inhibition of mitochondrial apoptosis in mice. J Clin Invest 2008, 118:2025-2038

7. Murakami $Y$, Ikeda $Y$, Yonemitsu $Y$, Onimaru M, Nakagawa K, Kohno R, Miyazaki M, Hisatomi T, Nakamura M, Yabe T, Hasegawa M, Ishibashi T, Sueishi K: Inhibition of nuclear translocation of apoptosisinducing factor is an essential mechanism of the neuroprotective activity of pigment epithelium-derived factor in a rat model of retinal degeneration. Am J Pathol 2008, 173:1326-1338
8. Tartaglia LA, Ayres TM, Wong GH, Goeddel DV: A novel domain within the $55 \mathrm{kd}$ TNF receptor signals cell death. Cell 1993, 74:845853

9. Nakazawa T, Matsubara A, Noda K, Hisatomi T, She H, Skondra D, Miyahara S, Sobrin L, Thomas KL, Chen DF, Grosskreutz CL, HafeziMoghadam A, Miller JW: Characterization of cytokine responses to retinal detachment in rats. Mol Vis 2006, 12:867-878

10. Zacks DN, Zheng QD, Han Y, Bakhru R, Miller JW: FAS-mediated apoptosis and its relation to intrinsic pathway activation in an experimental model of retinal detachment. Invest Ophthalmol Vis Sci 2004 , 45:4563-4569

11. Trichonas G, Murakami Y, Thanos A, Morizane Y, Kayama M, Debouck CM, Hisatomi T, Miller JW, Vavvas DG: Receptor interacting protein kinases mediate retinal detachment-induced photoreceptor necrosis and compensate for inhibition of apoptosis. Proc Natl Acad Sci U S A 2010, 107:21695-21700

12. Dubyak GR, el-Moatassim C: Signal transduction via P2-purinergic receptors for extracellular ATP and other nucleotides. Am J Physio 1993, 265:C577-C606

13. Sabirov RZ, Okada Y: ATP release via anion channels. Purinergic Signal 2005, 1:311-328

14. Burnstock G: Purinergic receptors in the nervous system. Curr Top Membr 2003, 54:307-368

15. Abbracchio MP, Burnstock G, Verkhratsky A, Zimmermann H: Purinergic signalling in the nervous system: an overview. Trends Neurosci 2009, 32:19-29

16. Wang X, Arcuino G, Takano T, Lin J, Peng WG, Wan P, Li P, Xu Q, Liu QS, Goldman SA, Nedergaard M: P2X7 receptor inhibition improves recovery after spinal cord injury. Nat Med 2004, 10:821-827

17. Khakh BS, North RA: P2X receptors as cell-surface ATP sensors in health and disease. Nature 2006, 442:527-532

18. Melani A, Turchi D, Vannucchi MG, Cipriani S, Gianfriddo M, Pedata F: ATP extracellular concentrations are increased in the rat striatum during in vivo ischemia. Neurochem Int 2005, 47:442-448

19. Abbracchio MP, Burnstock G: Purinoceptors: are there families of P2X and P2Y purinoceptors? Pharmacol Ther 1994, 64:445-475

20. Ralevic V, Burnstock G: Receptors for purines and pyrimidines. Pharmacol Rev 1998, 50:413-492

21. Surprenant A, Rassendren F, Kawashima E, North RA, Buell G: The cytolytic P2Z receptor for extracellular ATP identified as a P2X receptor (P2X7). Science 1996, 272:735-738

22. Ferrari D, Los M, Bauer MK, Vandenabeele $P$, Wesselborg $S$, Schulze-Osthoff K: P2Z purinoreceptor ligation induces activation of caspases with distinct roles in apoptotic and necrotic alterations of cell death. FEBS Lett 1999, 447:71-75

23. Denlinger LC, Fisette PL, Sommer JA, Watters JJ, Prabhu U, Dubyak GR, Proctor RA, Bertics PJ: Cutting edge: the nucleotide receptor P2X7 contains multiple protein- and lipid-interaction motifs including a potential binding site for bacterial lipopolysaccharide. J Immunol 2001, 167:1871-1876

24. Kong $Q$, Wang $M$, Liao Z, Camden JM, Yu S, Simonyi A, Sun GY, Gonzalez FA, Erb L, Seye CI, Weisman GA: P2X(7) nucleotide receptors mediate caspase-8/9/3-dependent apoptosis in rat primary cortical neurons. Purinergic Signal 2005, 1:337-347

25. Sperlagh B, Szabo G, Erdelyi F, Baranyi M, Vizi ES: Homo- and heteroexchange of adenine nucleotides and nucleosides in rat hippocampal slices by the nucleoside transport system. Br J Pharmacol 2003, 139:623-633

26. Deuchars SA, Atkinson L, Brooke RE, Musa H, Milligan CJ, Batten TF, Buckley NJ, Parson SH, Deuchars J: Neuronal P2X7 receptors are targeted to presynaptic terminals in the central and peripheral nervous systems. J Neurosci 2001, 21:7143-7152

27. Pannicke T, Fischer W, Biedermann B, Schadlich H, Grosche J, Faude F, Wiedemann P, Allgaier C, Illes P, Burnstock G, Reichenbach A: $P 2 X 7$ receptors in Muller glial cells from the human retina. J Neurosci 2000, 20:5965-5972

28. Brandle U, Kohler K, Wheeler-Schilling TH: Expression of the P2X7receptor subunit in neurons of the rat retina. Brain Res Mol Brain Res 1998, 62:106-109

29. Zhang $X$, Zhang $M$, Laties AM, Mitchell $\mathrm{CH}$ : Stimulation of $\mathrm{P} 2 \times 7$ receptors elevates $\mathrm{Ca} 2+$ and kills retinal ganglion cells. Invest Ophthalmol Vis Sci 2005, 46:2183-2191

30. Puthussery T, Fletcher EL: Synaptic localization of $P 2 X 7$ receptors in the rat retina. J Comp Neurol 2004, 472:13-23 
31. McLarnon JG, Ryu JK, Walker DG, Choi HB: Upregulated expression of purinergic P2X(7) receptor in Alzheimer disease and amyloid-beta peptide-treated microglia and in peptide-injected rat hippocampus. J Neuropathol Exp Neurol 2006, 65:1090-1097

32. Diaz-Hernandez M, Diez-Zaera M, Sanchez-Nogueiro J, Gomez-Villafuertes R, Canals JM, Alberch J, Miras-Portugal MT, Lucas JJ: Altered P2X7-receptor level and function in mouse models of Huntington's disease and therapeutic efficacy of antagonist administration. FASEB J 2009, 23:1893-1906

33. Peng W, Cotrina ML, Han X, Yu H, Bekar L, Blum L, Takano T, Tian GF, Goldman SA, Nedergaard M: Systemic administration of an antagonist of the ATP-sensitive receptor P2X7 improves recovery after spinal cord injury. Proc Natl Acad Sci U S A 2009, 106:12489-12493

34. Rodrigues EB, Meyer CH, Kroll P: Chromovitrectomy: a new field in vitreoretinal surgery. Graefes Arch Clin Exp Ophthalmol 2005, 243 291-293

35. Abrams JS, Roncarolo MG, Yssel H, Andersson U, Gleich GJ, Silver JE: Strategies of anti-cytokine monoclonal antibody development: immunoassay of IL-10 and IL-5 in clinical samples. Immunol Rev 1992, 127:5-24

36. Kayagaki N, Yamaguchi N, Nagao F, Matsuo S, Maeda H, Okumura K, Yagita $\mathrm{H}$ : Polymorphism of murine Fas ligand that affects the biological activity. Proc Natl Acad Sci U S A 1997, 94:3914-3919

37. Thresher RJ, Ehrenberg M, Machemer R: Gas-mediated vitreous compression: an experimental alternative to mechanized vitrectomy. Graefes Arch Clin Exp Ophthalmol 1984, 221:192-198

38. Irvine WD, Johnson MW, Hernandez E, Olsen KR: Retinal toxicity of human tissue plasminogen activator in vitrectomized rabbit eyes. Arch Ophthalmol 1991, 109:718-722

39. Enaida H, Sakamoto T, Hisatomi T, Goto Y, Ishibashi T: Morphological and functional damage of the retina caused by intravitreous indocyanine green in rat eyes. Graefes Arch Clin Exp Ophthalmol 2002, 240:209-213

40. Enaida H, Hisatomi T, Goto $Y$, Hata $Y$, Ueno A, Miura M, Kubota T, Ishibashi $\mathrm{T}$ : Preclinical investigation of internal limiting membrane staining and peeling using intravitreal brilliant blue G. Retina 2006 , 26:623-630

41. Nakazawa T, Hisatomi T, Nakazawa C, Noda K, Maruyama K, She H, Matsubara A, Miyahara S, Nakao S, Yin Y, Benowitz L, Hafezi-Moghadam A, Miller JW: Monocyte chemoattractant protein 1 mediates retinal detachment-induced photoreceptor apoptosis. Proc Natl Acad Sci U S A 2007, 104:2425-2430

42. Jiang LH, Mackenzie AB, North RA, Surprenant A: Brilliant blue $G$ selectively blocks ATP-gated rat P2X(7) receptors. Mol Pharmacol 2000, 58:82-88

43. Hu H, Lu W, Zhang M, Zhang X, Argall AJ, Patel S, Lee GE, Kim YC, Jacobson KA, Laties AM, Mitchell $\mathrm{CH}$ : Stimulation of the P2X7 receptor kills rat retinal ganglion cells in vivo. Exp Eye Res 2010, 91:425-432

44. Puthussery T, Fletcher E: Extracellular ATP induces retinal photoreceptor apoptosis through activation of purinoceptors in rodents. J Comp Neurol 2009, 513:430-440

45. Joseph SM, Buchakjian MR, Dubyak GR: Colocalization of ATP release sites and ecto-ATPase activity at the extracellular surface of human astrocytes. J Biol Chem 2003, 278:23331-23342

46. Pellegatti P, Falzoni S, Pinton P, Rizzuto R, Di Virgilio F: A novel recombinant plasma membrane-targeted luciferase reveals a new pathway for ATP secretion. Mol Biol Cell 2005, 16:3659-3665
47. Oike M, Kimura C, Koyama T, Yoshikawa M, Ito Y: Hypotonic stressinduced dual $\mathrm{Ca}(2+)$ responses in bovine aortic endothelial cells. Am J Physiol Heart Circ Physiol 2000, 279:H630-H638

48. Liu HT, Sabirov RZ, Okada Y: Oxygen-glucose deprivation induces ATP release via maxi-anion channels in astrocytes. Purinergic Signal 2008, 4:147-154

49. Langer D, Hammer K, Koszalka P, Schrader J, Robson S, Zimmermann $\mathrm{H}$ : Distribution of ectonucleotidases in the rodent brain revisited. Cell Tissue Res 2008, 334:199-217

50. Beigi R, Kobatake E, Aizawa M, Dubyak GR: Detection of local ATP release from activated platelets using cell surface-attached firefly luciferase. Am J Physiol 1999, 276:C267-C278

51. Nagasawa K, Escartin C, Swanson RA: Astrocyte cultures exhibit P2X7 receptor channel opening in the absence of exogenous ligands. Glia 2009, 57:622-633

52. Adriouch S, Bannas P, Schwarz N, Fliegert R, Guse AH, Seman M, Haag F, Koch-Nolte F: ADP-ribosylation at R125 gates the P2X7 ion channel by presenting a covalent ligand to its nucleotide binding site. FASEB J 2008, 22:861-869

53. Kadonosono K, Itoh N, Uchio E, Nakamura S, Ohno S: Staining of internal limiting membrane in macular hole surgery. Arch Ophthalmol 2000, 118:1116-1118

54. Burk SE, Da Mata AP, Snyder ME, Rosa RH Jr, Foster RE: Indocyanine green-assisted peeling of the retinal internal limiting membrane. Ophthalmology 2000, 107:2010-2014

55. Engelbrecht NE, Freeman J, Sternberg P Jr, Aaberg TM Sr, Aaberg TM Jr, Martin DF, Sippy BD: Retinal pigment epithelial changes after macular hole surgery with indocyanine green-assisted internal limiting membrane peeling. Am J Ophthalmol 2002, 133:89-94

56. Uemura A, Kanda S, Sakamoto Y, Kita H: Visual field defects after uneventful vitrectomy for epiretinal membrane with indocyanine green-assisted internal limiting membrane peeling. Am J Ophthalmol 2003, 136:252-257

57. Kawahara S, Hata Y, Miura M, Kita T, Sengoku A, Nakao S, Mochizuki $Y$, Enaida $\mathrm{H}$, Ueno A, Hafezi-Moghadam A, Ishibashi T: Intracellular events in retinal glial cells exposed to ICG and BBG. Invest Ophthalmol Vis Sci 2007, 48:4426-4432

58. Hisatomi T, Enaida $\mathrm{H}$, Matsumoto $H$, Kagimoto $T$, Ueno A, Hata $Y$, Kubota T, Goto Y, Ishibashi T: Staining ability and biocompatibility of brilliant blue G: preclinical study of brilliant blue $\mathrm{G}$ as an adjunct for capsular staining. Arch Ophthalmol 2006, 124:514-519

59. Enaida H, Hisatomi T, Hata Y, Ueno A, Goto Y, Yamada T, Kubota T, Ishibashi $\mathrm{T}$ : Brilliant blue $\mathrm{G}$ selectively stains the internal limiting membrane/brilliant blue G-assisted membrane peeling. Retina 2006, 26:631-636

60. Farah ME, Maia M, Rodrigues EB: Dyes in ocular surgery: principles for use in chromovitrectomy. Am J Ophthalmol 2009, 148:332-340

61. Rodrigues EB, Penha FM, de Paula Fiod Costa E, Maia M, Dib E, Moraes M Jr, Meyer CH, Magalhaes O Jr, Melo GB, Stefano V, Dias $A B$, Farah ME: Ability of new vital dyes to stain intraocular membranes and tissues in ocular surgery. Am J Ophthalmol 2010, 149:265-277

62. Kumar A, Gogia V, Shah VM, Nag TC: Comparative evaluation of anatomical and functional outcomes using brilliant blue $G$ versus triamcinolone assisted perform peeling in macular hole surgery in Indian population. Graefes Arch Clin Exp Ophthalmol 2011, 249:987995 